\title{
Additional Surgery for new Loco-Regional Tumor Event Not Evaluated
}

National Cancer Institute

\section{Source}

National Cancer Institute. Additional Surgery for new Loco-Regional Tumor Event Not

Evaluated. NCI Thesaurus. Code C162598.

The need for additional surg ery for a new loco-regional tumor event was not evaluated. 